\title{
Examining the uptake of low-carbon approaches within the healthcare sector: case studies from the National Health Service in England
}

\author{
Terry Tudor*1, Jerome Baddley², Laura Mayhew-Manchón ${ }^{3}$ \\ ${ }^{1}$ School of Science and Technology, University of Northampton, Northampton, UK \\ ${ }^{2}$ Nottingham Energy Partnership, Nottingham, UK \\ ${ }^{3}$ The Environmental Technology Centre. University of Nottingham, Nottingham, UK
}

Received: June 19, 2015

DOI: $10.5430 /$ ijh.v1n1p61
Accepted: July 28, 2015

Online Published: August 17, 2015

\begin{abstract}
The National Health Service (NHS) in the UK, is one of the largest organisations in Europe and indeed the world. It therefore has a significant ecological footprint. As a result there are key corporate, financial and environmental targets that the organisation is expected to meet as a means of reducing resource consumption. Using a case study approach, this manuscript examines best practice examples for the uptake of low-carbon strategies for energy conservation. These strategies included sustainable procurement, use of renewable energy technologies, supply chain management, use of building management systems, renegotiating energy contracts, undertaking energy audits, and behaviour change, to realise significant financial, as well as energy and carbon savings. A key focus was management of water resources, including the use of recycling and recovery of heat. The implications of the findings for building ecological and financial resilience within the organisation are also discussed.
\end{abstract}

Key Words: National Healthcare Services, Sustainability, Low-carbon technologies, Energy conservation, Healthcare facilities, UK

\section{INTRODUCTION}

Due to increasing global challenges (e.g. rising populations, urbanisation, economic recessions, climate change and resource security), there is a growing need to develop governance strategies for more sustainable resource management. ${ }^{[1-7]}$ Within this overarching context, there is an increasing realisation of the need for enhanced sustainability within the healthcare sector. ${ }^{[8-12]}$ For example, climate change is one of the biggest threats facing the United Kingdom (UK) and globally. ${ }^{[3,6,12,13]}$ Changing weather patterns are predicted to have significant implications for how the public health and social care systems in the UK operate. ${ }^{[14]}$ According to Appleby and Naylor, ${ }^{[11]}$ over the next 50 years, health and social care could become one of the largest sectors of the economy and consume the majority of government spending. It is likely to account for around $£ 1$ trillion of around $£ 4.8$ trillion by 2062 , up from around $£ 0.1$ trillion of $£ 1.5$ trillion in 2016. ${ }^{[15]}$

The National Health Service (NHS) employs around 2 million staff and caters to a population of 52 million, or around 3 million per week, across the UK. ${ }^{[16]}$ According to the Sustainable Development Unit (SDU), ${ }^{[16]}$ the vision for the NHS

\footnotetext{
*Correspondence: Terry Tudor; Email: Terry.Tudor@northampton.ac.uk; Address: School of Science and Technology, University of Northampton, Northampton, UK.
} 
is to have "a low carbon quality healthcare environment that is sustainable, resilient, and safeguards high quality patient care". A sustainable health service will use more efficient facilities, lower carbon processes, and less energy intensive care pathways. A significant proportion of healthcare delivery - including prevention, diagnosis, treatment, long term care, and rehabilitation - is likely to move closer to the home. Thus shifting the clinical care pathways away from acute, primary care and mental health facilities, into more disperse household settings. ${ }^{[12]}$ This will support the trend of moving as much treatment and professional care as possible to prevention and empowerment.

Using a case study approach of energy conservation, this study set out to understand how best the NHS could move towards this more low-carbon approach, and to identify some of the key challenges in the process.

\section{ENERGY MANAGEMENT IN THE HEALTH- CARE ORGANISATIONS}

Electricity can account for over $50 \%$ of a hospital's energy costs and with the increased use of specialist medical equipment that generally relies on electricity, consumption is set to increase. ${ }^{[17]}$ Lighting can account for over $20 \%$ of the total energy use or over $35 \%$ of the electricity used in a typical hospital. Good lighting design can reduce costs, decreasing internal heat gains and the need for air conditioning. The European Energy Performance of Buildings Directive (EPBD) promotes improvement in the energy performance of buildings. ${ }^{[18]}$ It requires hospitals with floor areas over $1,000 \mathrm{~m}^{2}$ to produce and display Energy Performance Certificates (EPCs) in a prominent and public location.

\section{Energy management in the NHS}

Healthcare buildings in England consume over $£ 410$ million worth of energy annually, ${ }^{[16]}$ and are also responsible for substantially contributing to climate change through the release of 3.8 million tonnes of carbon every year. Energy usage constitutes an increasingly area of spend for the NHS. The estimated combined UK health, public health and social care carbon footprint is 32 million tonnes $\left(\mathrm{MtCO}_{2 e}\right){ }^{[6]} \mathrm{It}$ is responsible for $25 \%$ of all public sector greenhouse gas emissions in England and is one of the most energy intensive organisations in the UK, spending $£ 75$ million on its annual energy bills. ${ }^{[19]}$ According to $\mathrm{SDU}^{[20]}$ there are three key factors that influence these emissions, primarily procurement of pharmaceuticals and medical instruments, as well as travel and energy usage in buildings. A more sustainable approach is therefore crucial to meet targets and mitigate against the impacts of expanding provision of healthcare. ${ }^{[21]}$

There are a number of corporate, financial and environ- mental drivers for the NHS to engage with the sustainability agenda. ${ }^{[12,22]}$ For example, the Public Services (Social Value) Act (2012) requires all commissioners of public services to take into account economic, social and environmental value, not just price, when buying goods and services. Under the Act, Clinical Commissioning Groups (CCGs) must take these factors into consideration as part of the competitive commissioning process to drive through innovation and carbon reduction, and to ensure value for money. Sustainable development and carbon management are corporate responsibilities in the NHS and are integral to the governance processes for achieving compliance and high quality healthcare. ${ }^{[12]}$ The Climate Change Act sets out a target of a $34 \%$ reduction in carbon emissions by 2020 , from a 1990 baseline, and also provides incentives through the Carbon Reduction Commitment (CRC) (an emissions trading scheme). ${ }^{[23]}$ NHS organisations have a commitment to meet a $10 \%$ reduction by 2015 and the mandatory governmental targets for emission reductions of $34 \%$ by 2020 and $80 \%$ by 2050 . Since 2008 , all NHS sites over $1,000 \mathrm{~m}^{2}$ are legally mandated to display EPCs, under the provisions of the Energy Performance of Buildings Regulations 2007. [16] The NHS was expected to achieve efficiency savings of around $£ 15-20$ billion savings during the period of Government's financial spending review of $2011-2014 .^{[24]}$ They are mandated to include sustainability and climate change in their annual reporting to Monitor (the Independent Regulator of NHS Foundation Trusts) and the Department of Health (DH). In light of the progress made between 1990 - 2013, the NHS still has a $28 \%$ reduction to meet if it is to achieve its 2020 target. $^{[12]}$ The Green Investment Bank suggests that energy efficiency measures could reduce energy costs by around $20 \%$ per annum (giving a saving of $£ 150$ million). The measures would also reduce greenhouse gas emissions by $25 \%$, by 2015 , well above the NHS's $10 \%$ target. $^{[19]}$

\section{METHODS}

The study was undertaken in two main phases:

First, the aim was to gain an understanding of trends in energy consumption patterns within the UK healthcare sector. The NHS is the key stakeholder within the sector and so this was chosen as the main focus. Data on energy consumption were obtained via the publically available database, the Estates Return Information Collection (ERIC). ERIC is the official dataset of performance by the NHS estates and facilities departments, based on annual returns to the Department of Health by these entities. Data over a five year period from 2008/9 - 2012/3 were collected from the database for analysis. This period was chosen as it provides the most recent data and also represents a long enough period to evaluate 
any key trends. Data on electricity, gas, oil and coal consumed were collected as these related to energy consumption at the sites. In addition, costs for each year were also collected for the period under review. As the data were from different hospital sources and years, the data for 2008/9 and 2009/10 were in Giga Joules (GJ), while those in 2010/11 and 2011/12 were in kilo Watt hours (kWh). Therefore to ensure consistency, all of the units were changed to $\mathrm{kWh}$. The annual totals for each factor (i.e. electricity, coal and costs, etc.), were simply totalled, in order to compare the energy consumption with the associated costs.

Second, a review of both the academic and industry literature was undertaken. Following on from the first phase which identified trends in energy consumption, this phase sought to identify and examine best practice examples that have been able to show a demonstrable reduction in energy consumption. It was limited to the period $2008-2014$, in order to provide up to date information, and also to map unto the period of the data from the ERIC returns. An initial search of the academic sources (e.g. ScienceDirect), was undertaken, using key words such as "healthcare organizations", "energy management", "energy conservation", "UK" and "NHS". However, while there were some studies on energy conservation within organisations $\left(e . g .,{ }^{[25,26]}\right.$ there were no relevant studies found related to the healthcare sector, particularly in the UK. Therefore the focus was shifted to the grey literature, with an emphasis on sources related to the UK health and social care sector, such as the NHS (including the Sustainable Development Unit - SDU), as well as relevant government agencies (e.g. the Department of Energy and Climate Change - DECC, the Waste and Resources Action Programme - WRAP). In addition, the websites of hospitals known to the authors that have developed energy conservation initiatives, for example which have won awards, were also searched. Again the focus was on energy conservation initiatives within the healthcare sector, particularly in the UK. While the focus was on the UK, other relevant countries there were also searched. Google was primarily used for the generic searches, while the names of the hospitals were used for the more specific sites known to the authors. The key words for the generic search were similar to those used for the academic search. The materials were read and the aim of the content analysis was not only to identify any relevant initiatives, but the strategies employed to implement them and key environmental and economic measures of success.

\section{Results}

\subsection{Energy consumption within the NHS}

As shown in Figure 1, the overall energy consumption has reduced significantly since 2008/9. Gas is by far the key

Published by Sciedu Press source of energy, accounting for up to $95 \%$ in 2008/9, and on average approximately $67 \%$, between $2010 / 13$.

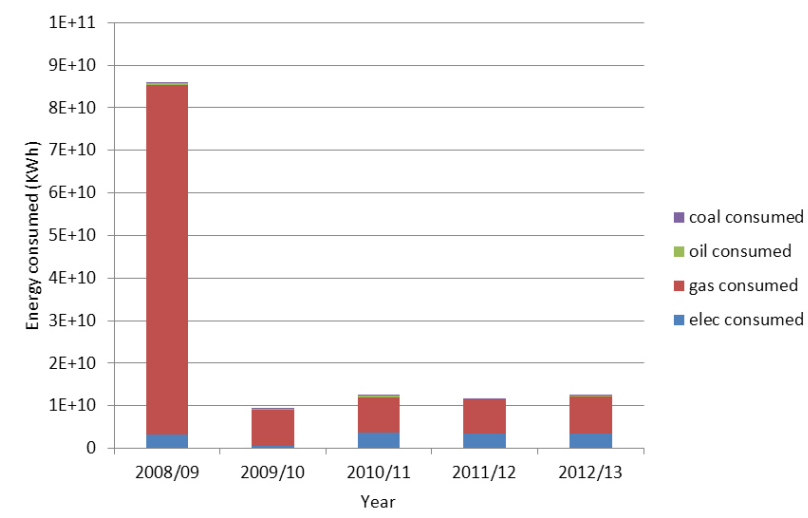

Figure 1. Key sources of energy within the NHS between 2008/9 - 2012/13

Figure 2 demonstrates that similarly to energy consumption, during the period of study, the related costs fell dramatically between 2008/9 and 2009/10. However, since 2009/10, costs have risen sharply, to reach near to previous levels.

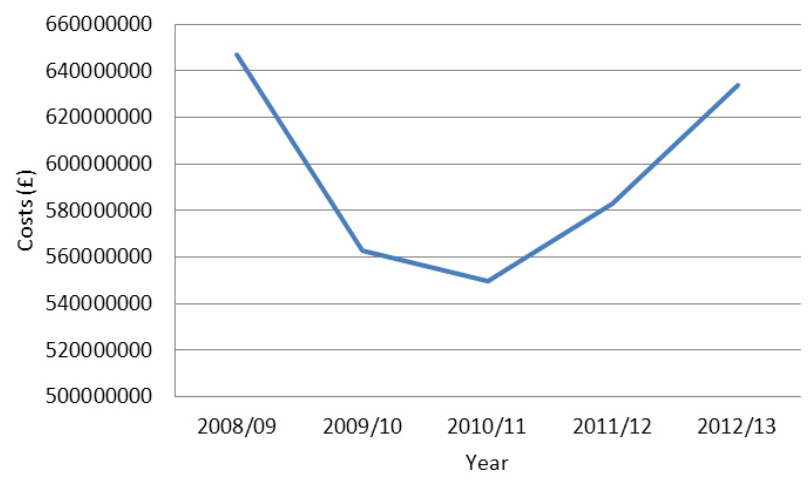

Figure 2. Changes in costs of energy consumption within the NHS between 2008/9 - 2012/13

\subsection{Strategies for conserving energy in healthcare}

Messelbeck and Whaley ${ }^{[27]}$ argued that improving the environmental impact of the health care industry should start with the health care delivery institutions, with an emphasis on the supply chain and considering the role of environmental management systems such as ISO 14001 throughout the entire chain. SDU ${ }^{[17]}$ notes that reduction in energy usage could be achieved through reducing unnecessary usage, through technological approaches and behaviour change, increasing energy efficiency and increasing the use of low carbon energy. Carbon Trust ${ }^{[17]}$ outlines a number of areas for focus: (1) water and the related energy costs within healthcare facilities can be significant. Conservation of water, through for 
example, recycling of water or the heat from steam-heated laundries, or heat recovery through heat exchangers, reduces the pumping requirement, which saves energy and reduces carbon emissions; (2) use of combined heat and power (CHP) can reduce energy bills by around $20 \%-30 \%$, provided the unit is designed to meet the building's seasonal demands for electricity and heating; (3) Setting appropriate temperatures and ensuring that heating equipment and controls are operated and managed correctly; (4) it is possible to save up to $30 \%$ on heating costs through the implementation of some simple energy saving measures such as encouraging staff to report when it is too hot or too cold, zoning (i.e. different timings and temperatures in different areas of a site), checking for damp in surfaces, implementing staff awareness campaigns, keeping external doors open only when necessary, regular servicing of boilers and pipe works, as well as using upgraded controls (e.g. compensators), a "dead band" - a wide gap between the temperatures at which heating and cooling cut in, and water saving devices (e.g. tap restrictors); (5) use of a Building Energy Management System (BMS or BEMS), which enables control and monitoring of building services performance (including heating, ventilation and air conditioning), can reduce total energy costs by $10 \%$ or more.

\subsubsection{Energy conservation initiatives in healthcare}

As demonstrated in Table 1, healthcare sites in the UK have been able to develop initiatives to realise significant reductions in energy consumption. These have led to significant reductions in carbon emissions as well as financial savings.

Table 1. Case studies of energy efficiency mechanisms employed by UK healthcare facilities

\begin{tabular}{ll}
\hline NHS Organisation & Savings \\
\hline Rotherham NHS Foundation Trust & $\begin{array}{l}30 \% \text { reduction in energy, or } £ 4,600 \text { per } 40 \text { beds over } 10 \text { years and a reduction in } \\
\text { maintenance of more than } 80 \%\end{array}$ \\
$\begin{array}{l}£ 688,000 \text { and } 1.627 \text { tonnes of carbon emissions, annually } \\
\text { Birmingham Heartlands and Solihull NHS Trust }\end{array}$ & $40 \%-50 \%$ reduction in carbon emissions \\
Pilgrim Hospital & $£ 80,000$ \\
Frincess Alexandra Hospital & $£ 17,000 /$ annum \\
Barts Health NHS Trust & Reduced lighting being left on by $40 \%$, saving $£ 13,714 /$ annum, and doors being left \\
& open by $18 \%$, saving $£ 7,801$ \\
East Midlands NHS & Total annual potential carbon savings of $96,013 \mathrm{~kg} \mathrm{CO}_{2 \mathrm{e}}$, with energy saving potential \\
& of $380,864 \mathrm{kWh}$. Financial saving potential of between $£ 77,259-163,921$ \\
\hline
\end{tabular}

\subsubsection{Strategies for successful implementation of energy conservation}

The healthcare sites surveyed employed a range of strategies in order to reduce their energy consumption, including the use of sustainable procurement, use of energy conservation technologies and staff engagement.

Behaviour change: Barts Health NHS Trust in London, worked in conjunction with charity, Global Action Plan to develop "nudge" activities for staff to reduce energy consumption. ${ }^{[28]}$ They activities included targeted educational programmes, to switch off equipment and lights when not in use. It was realised that simply focusing on energy conservation was not enough, thus the benefits of improving the patient experience were also incorporated. In addition to the environmental and economic savings, patient experience also improved with fewer reports of disturbance.

Sustainable procurement: Rotherham employed a sustainable procurement system, known as Forward Commitment Procurement (FCP), to purchase more energy efficient lighting. FCP enables organisations to manage their supply chains by engaging with their suppliers and providing credible in- formation about their future requirements and purchases. Through this dialogue it is possible for suppliers to deliver what is needed, when it is needed, at a price that is affordable. Energy $\mathrm{Star}^{[30]}$ states that healthcare facilities in the USA spend around $£ 4.2 \mathrm{~B}$ annually on energy management. Most do not have a strategic master energy plan, use commissioning of existing buildings or follow the Green Guide for Health Care to monitor their baseline energy performance and only $28 \%$ of those sampled performed an annual energy audit. However, for-profit hospitals, medical offices, and nursing homes could increase their earnings per share a penny by reducing energy costs by $5 \%$. As a result of this potential, hospitals have sought to conduct energy audits (40\%), set energy budget and performance targets and monitoring them annually, participating in the programme Energy Star, and renegotiate their energy contracts in the retail markets, as ways of saving money. ${ }^{[30,31]}$

Technological approaches: Many NHS organisations employed technological approaches. These approaches sought to either reduce energy usage, generate renewable sources of energy or a combination of the two. The East Midlands NHS organisations employed the use of various energy con- 
servation technologies including, automatic meter reading and voltage optimisation. In addition, two electric vehicles were also trialled. Sustainable procurement of feed supplies was also trialled at one site. Workshops were also hosted to provide training for staff and enable networking opportunities. The financial savings potential was based on four different scenarios of the Feed-In-Tariff (FITs) rates at the time of the project. ${ }^{[29,32,33]}$ FITs are an incentive scheme introduced by UK Government in 2010, to encourage the uptake of renewable energy technologies. ${ }^{[34]}$ Similarly to in the East Midlands, the Birmingham Heartlands and Solihull NHS Trust utilised a CHP system as a means of generating its own electricity. While Pilgrim Hospital used biomass boilers to also serve as a renewable source of energy, rather than depending solely on fossil fuels. Alternatively, the Princess Alexandra Hospital installed light emitting diode (LED) lighting throughout the hospital as a means of reducing its energy consumption. Freeman Hospital, sought to link its ventilation system to a building management system and passive infrared (PIR) detectors. Thus Freeman Hospital was able to automate and control its ventilation system and by extension the energy used. According to Energy Star, ${ }^{[30]}$ in the USA, technologically focused approaches have included using LED exit signs, and electronic ballast and energy-efficient lamps (75\%), buying Energy Star-certified products (55\%), upgrading building control systems (53\%) and implementing energy conservation programs (49\%). However, challenges in the USA have included limitations in finance, aging buildings and lack of an immediate return on investment on capital projects such as fuel cells, and photovoltaic or solar thermal systems. Some of these challenges are also being faced in the UK. ${ }^{[29,33]}$

\section{DisCuSSION}

The health and social care sector in the UK has a significant ecological footprint. As a result, it faces increasingly stringent financial and environmental targets to encourage the development of more sustainable clinical care pathways, with reduced resource consumption and greenhouse gas emissions. ${ }^{[6,12,19]}$ Figures 1 and 2 illustrated increased energy consumption, coupled with sharply rising costs. These increased prices are most likely linked to sharp rises in global oil and gas prices during the period of 2011/13. Gas accounted for around $2 / 3$ of the sources of energy. The use of more low carbon approaches, including energy conservation can play a key role in minimising the sector's contribution to climate change, help its organisations to become more energy cost-resilient, and support the enhancement of the health and wellbeing of the society. ${ }^{[16,19,35]}$

This study has identified that for a more low carbon approach to be realised, it is important that a range of options be employed (Carbon Trust, 2010). These include sustainable procurement, use of renewable energy technologies, supply chain management, use of building management systems, renegotiating energy contracts, undertaking energy audits, as well as behaviour change strategies aimed at staff engagement. A key factor to focus on was the management of water resources (including the use of recycling and recovery of heat), as heating of water is evidently a major consumer of energy in the sector.

However, the development of a more sustainable approach is not without challenges. While there are examples of best practice across the sector and indeed outside of the UK, there is often limited awareness and not enough collaboration. There is a need therefore for greater collaboration between stakeholders and sharing of this best practice information. In this way, more effective energy management systems could be put in place from the stage of commissioning buildings and services, through to their use. For example, Peterman et al. (2014) posit the need for government led interorganisational alliance networks. Such networks are comprised of government agencies, trade associations, private entities and government funded research laboratories, which serve as a platform to leverage stakeholders, share best practice, strategise, validate new technologies and promote new publically funded research.

Similarly to HFM and ASHE, ${ }^{[31]}$ the NHS faces significant funding shortages and an aging building stock. These factors are limiting investment in "large scale" capital energy projects. A related point is that the East Midlands' Carbon Reduction project coincided with Government's review of FITs. A key measure in the review was substantial cuts to the FITs income rates (with subsequent doubling of payback periods), together with changes to eligibility. This served to discourage most of the NHS organisations involved in the project from progressing to the installation stage. ${ }^{[29,33]}$ Thus Government policies and changes in these play a crucial role in the uptake of renewable technologies.

It is important to incorporate energy conservation within overarching strategic plans of sites and to ensure that there is commitment from senior management in the form of resources (i.e. finance and personnel), if conservation strategies are to be effective. Implementation of large scale conservation strategies, such as the development of technologies should be seen as an investment which while they may not always realise significant short term financial savings, can as demonstrated with time, achieve significant financial and carbon savings. Pressure to reduce costs and meet health services targets means that too often environmental manage- 
ment decisions within the NHS tend to be made looking at short-term gain, on a small-scale project basis, rather than long-term. This therefore leads to hesitancy in investment and limitations in success.

At a wider level, it is crucial that in the implementation of conservation strategies, that the safety and wellbeing of patients and staff be maintained. Thus consideration should be given to the likely impacts on ventilation and indoor air quality, increased $\mathrm{CO}_{2}$ levels (which may affect ability to concentrate and mood, cause drowsiness) and increased airborne pathogen levels. Reduced electric heating capability would reduce the rate of hot water production, possibly delaying procedures by increasing the time required to sterilise or autoclave equipment, etc. In an emergency, or at times of high demand, electrically heated tap water might fail to reach the temperature required to kill pathogens such as Legionella reliably. Clinical staff should also be consulted regarding the desirability of reducing light levels in diagnostic areas, thermal comfort and ventilation levels, as these may pose risks to health and wellbeing, or affect the operational capabilities of the hospital. The risks posed should be assessed on a site by site basis and a multi-disciplinary approach taken to quantify and mitigate unintended consequences.

The development and implementation of more sustainable approaches can lead not only to environmental compliance, but also to costs savings. ${ }^{[11]}$ Indeed, the SDU ${ }^{[12]}$ argues that reduction in energy usage would contribute to reducing carbon emissions and energy costs and demand. This would help to future-proof both the infrastructure and provide the opportunity to transform service delivery within the sector. Efforts should be spread across building energy use, travel and procurement of goods and service. ${ }^{[12]}$ This would enable the development of a more sustainable health service that uses more efficient facilities, low-carbon processes and less energy intensive care pathways. ${ }^{[16]}$ Adoption of low-carbon approaches can provide a physical representation of the commitment that healthcare organisations make to operate in more sustainable ways, sending a strong message to service users, patients, staff, visitors and other stakeholders, and providing a symbol for the local community. Furthermore, having a visual, working example of sustainability in the built environment could inspire other public sector organisations and partners to do likewise.

\section{Conclusions}

The size and the related resource demands of the health and social care sector in the UK are substantial, and these factors are anticipated to rise in coming years. ${ }^{[12]}$ This is there- fore expected to have an impact on resource consumption, especially energy. As argued by the SDU, ${ }^{[12]}$ use of more low carbon approaches can contribute to reduced emissions and energy bills, coupled with increased low carbon energy within the healthcare sector in the UK. In this way, healthcare organisations could reduce their impacts on the environment, realise financial savings, and comply with their financial and environmental targets.

However, the NHS is a complex system, and care must be taken to ensure that minimising energy consumption does not negatively impact upon public health. In addition, changes in processes and practices have to be set within the context of a huge organisation, whose primary role is to deliver healthcare to millions of patients, and which has increasingly stringent financial and strategic pressures. Notwithstanding these issues, the use of low-carbon approaches such as renewable energy technologies, can deliver cost savings, a reduced carbon footprint, allow statutory and compliance obligations to be met, and improve energy resilience. ${ }^{[6,37]}$ Indeed, these adaptation actions could improve the resilience of both healthcare services and the communities served by them. They could also feed into national adaptation plans through for example, joint health and wellbeing strategies (JHWS), joint strategic needs assessments (JSNA) and Commissioning Plans. ${ }^{[14]}$

Within the coming decades, the UK and indeed the world face potentially significant and disastrous impacts as a result of changes to climate. These are expected to affect all sectors of society, as well as the manner in which it interacts with its communities and vice versa. Healthcare organisations work at the very heart of the communities which they serve. As a result, they are uniquely placed to lead by example and inspire others to also act as good corporate citizens and use innovation to improve performance and service delivery. This study has identified examples of best practice and also highlighted issues to be addressed. If effectively put into practice these approaches could potentially help NHS organisations to build their ecological and financial resilience, and also support the enhancement of the health and wellbeing of society. Given the wide footprint of the sector, the wider adoption of these measures could assist in its adaptation and mitigation strategies to climate change, through not only reduced impacts on the environment during service provision, but also enhanced provision and contribution to economic growth. Ultimately, a sustainable health service will lead to more efficient use of resources and more sustainable clinical care pathways. 


\section{REFERENCES}

[1] Tudor TL. Sustainable waste management and climatic change, in: Conservation of Natural Resources. Environmental Science, Engineering and Technology. Kudrow N.J. (Ed.). Nova Publishers. 237247. ISBN 978-1-60741-178-9. 2009.

[2] UNEP (United Nations Environment Programme). Year book: emerging issues in our global environment. Available from: http://www . unep.org/yearbook/2012/. 2012 Accessed on 10/4/2014

[3] Defra (Department for Environment, Food and Rural Affairs). Natural environment white paper. HMSO. London: England. 2011.

[4] Cossu R. Waste management, energy production, healthcare: amazing similarities. Waste Management. (Editorial). 2011; 1671-1672. PMid: 21601440.

[5] Baker JL. Climate change, disaster risk, and the urban poor: cities building resilience for a changing world. Washington, DC: World Bank. 2012. http://dx.doi.org/10.1596/978-0-8213-884 5-7

[6] SDU (Sustainable Development Unit). Sustainable, resilient, healthy people and places: a sustainable development strategy for the NHS, public health and social care system. 2014a. Available from: http://www.sduhealth.org.uk/documents/publications/ $2014 \% 20$ strategy $\% 20$ and $\% 20$ modulesNewFolder/Strategy_ FINAL_Jan2014.pdf . Accessed on 10/4/2014.

[7] Adger WN, Hodbod J. Ecological and social resilience. In: Atkinson G, Dietz S, Neumayer E, Agrawala M. (Eds.) Handbook of Sustainable Development, Cheltenham: Elgar; 2014. http://dx.doi .org /10.4337/9781782544708.00014

[8] CBO (Congressional Budget Office). The long-term outlook for health care spending: sources of growth in projected federal spending on Medicare and Medicaid. Washington DC: Congress of the United States Congressional Budget Office. 2007 Available from: www.cbo.gov/sites/default/files/cbofiles/f tpdocs/87xx/doc8758/11-13-lt-health.pdf . Accessed on $10 / 4 / 2014$.

[9] Przywara B. European economy. Projecting future health care expenditure at European level: drivers, methodology and main results. Economic papers 417. Brussels: European Commission. 2010. Available from: http://ec.europa.eu/economy_finance/pub lications/economic_paper/2010/pdf/ecp417_en.pdf

[10] Astolfi R, Lorenzoni L, Oderkirk J. Informing policy makers about future health spending: a comparative analysis of forecasting methods in OECD countries. Health Policy. 2012; 107(1): 1-10. PMid: 22682763. http://dx.doi.org/10.1016/j.healthpol. 2012. 05.001

[11] Appleby J. Spending on health and social care over the next 50 years. Why think long term? The Kings Fund. London. 2013. Available from: http://www.kingsfund.org.uk/sites/files/kf/fi eld/field_publication_file/Spending $\% 20$ on $\% 20$ healt h\%20...\%2050\%20years $\% 201$ ow $\% 20$ res $\% 20$ for $\% 20$ web.pdf. Accessed on 17/4/2014.

[12] SDU (Sustainable Development Unit). Sustainable, resilient, health people and places. Module: carbon hotspots. 2014b. Available from: http://www.sduhealth.org.uk/documents/publications/ $2014 \% 20$ strategy $\% 20$ and $\% 20$ modulesNewFolder/MODULE_ca rbon_hotspots_FINAL.pdf. Accessed on 10/4/2014.

[13] IPPC. Climate change 2014: impacts, adaptation and vulnerability. Geneva: Switzerland. 2014. Available from: http://ipcc-wg2.g ov/AR5/report/

[14] SDU (Sustainable Development Unit). Sustainability in the NHS: Health Check 2012. 2012c. Available from: http://www . sduhea lth.org.uk/documents/publications/Sustainability_i
n_the_NHS_Health_Check_2012_On-Screen_Version.pdf. Accessed on 25/02/2014

[15] OBR (Office for Budget Responsibility). Office for Budget Responsibility: economic and fiscal outlook. Report. Cm 8303. Norwich: HMSO. 2012. Available from: http://budgetresponsibility.independent.gov.uk/ wordpress/docs/March-2012-EF01.pdf. Accessed on $17 / 4 / 2014$

[16] SDU (Sustainable Development Unit). Energy and carbon management. 2012a. Available from: http: //www. sduhealth.org.uk/documents/resources/Ext _Ch_energy_and_carbon_management.pdf. Accessed on 25/02/14.

[17] Carbon Trust. Healthy budgets through energy efficiency. HMSO London. 2010.

[18] EC (European Commission). Directive 2010/31/EU: The European energy performance of buildings directive. Brussels. 2010.

[19] GIB (Green Investment Bank). A healthy saving: energy efficiency and the NHS. London: England. 2014.

[20] SDU (Sustainable Development Unit). Under the weather: improving health, wellbeing and resilience in a changing climate. 2014c.

[21] Campbell-Lendrum D, Bertollini R, Neira M, et al. Health and climate change: a road map for applied research. The Lancet. 2009; 373(9676): 1663-1665. http://dx.doi.org/10.1016/S0140-6 736 (09) 60926-0

[22] Tudor TL. The NHS and the sustainability agenda. Waste Research Management. 2013; 166(1): 38-42. http://dx.doi.org/10.16 80/warm. 12.00016

[23] DECC (Department of Energy and Climate Change). The Climate Change Act. HMSO. London. England. 2008.

[24] Nicholson D. NHS Chief Executive's annual report. 2009. Available from: http://www.healthcare-today.co.uk/doclibr ary/documents/pdf/215_the_year_2008-09.pdf. Accessed on $10 / 4 / 2014$

[25] Gliedt T, Hoicka CE. Energy upgrades as financial or strategic investment? Energy Star property owners and managers improving building energy performance. Applied Energy. 2015; 147: 430-443. http://dx.doi.org/10.1016/j.apenergy . 2015.02.028

[26] Li X, Tan H, Rackes A. Carbon footprint analysis of student behaviour for a sustainable university campus in China. Journal of Cleaner Production. 2015; 106(1): 97-108. http://dx.doi.org/1 $0.1016 / j$.jclepro.2014.11.084

[27] Messelbeck J, Whaley M. Greening the healthcare supply chain: triggers for change, models for success. Corporate Environmental Strategy. 1999; 6(1): 38-45. http://dx.doi.org/10.1016/S10 66-7938 (99) 90028-3

[28] SDU (Sustainable Development Unit). Energy and carbon management case studies. 2014d Available from: http://www.sduh ealth.org.uk/resources/case-studies.aspx. Accessed on $16 / 12 / 2014$

[29] Mayhew-Manchón L, Baddley J, Nma E, et al. NHS East Midlands Carbon Reduction Project Phase II - Report on the Renewable Energy Assessment (REA) element of the 'Energy in NHS Estates' pilot (1a) - Findings and recommendations. Nottingham Energy Partnership. 2012a. Available from: http://www . nottenergy . com/images/uploads/pdfs/NEP _2012_EM_NHS_CRP_Phase_II_1a_REA_pilot_report.pdf. Accessed 25/02/14.

[30] Energy Star. Healthcare: an overview of energy use and energy efficiencies opportunities. 2014. Available from: www. energystar.g ov/healthcare 
[31] HFM (Health Facilities Management) and ASHE. Hospital energy management survey. 2011. Available from: http: //www.hfmmagazine.com/display/HFM-news-article.d html?dcrPath=/templatedata/HF_Common/NewsArticle/d ata/HFM/Magazine/2011/Jul/0711HFM_FEA_CoverStory. Accessed on 18/07/2014.

[32] Baddley J. NHS East Midlands Carbon Reduction Project Phase I - Report on Footprinting, analysis and recommendations. Nottingham Energy Partnership. 2010. Available from: http://www.nottenergy.com/images/uploads/pdfs /EM_Carbon_Reduction_Project_Phase_I_Report.pdf. Accessed 25/02/14.

[33] Mayhew-Manchón, L, Baddley J, Nma E, et al. NHS East Midlands Carbon Reduction Project Phase II Report on the Automatic Meter Reading (AMR) element of the 'Energy in NHS Estates' pilot (1b) - Findings and recommendations. Nottingham Energy Partnership. 2012b. Available from: http://www . nottenergy . com/images/uploads/pdfs/NEP _2012_EM_NHS_CRP_Phase_II_AMR_pilot_1b_REPORT.pdf. Accessed 25/02/14.

[34] DECC (Department of Energy and Climate Change). Feed-inTariffs. HMSO. London. England. 2010.

[35] SDU (Sustainable Development Unit). Case study: Princess Alexandra Hospital. 2012b. Available from: http://www.sduhealth. org.uk/documents/case_study/1242996017_kdpw_energy _-_princess_alexandra_hospital_solar_panels.pdf

[36] Peterman A, Kourula A, Levitt R. Balancing act: government roles in an energy conservation network. Research Policy. 2014; 43: $1067-$ 1082. http://dx.doi .org/10.1016/j.respol.2013.12.007

[37] Appleby J, Naylor C. Sustainable health and social care: connecting environmental and financial performance. 2012. Available from: http://www.kingsfund.org.uk/sites/files/kf/field/ field_publication_file/sustainable-health-social-c are-appleby-naylor-mar2012.pdf. Accessed on 17/4/2014. 